\title{
Maternal and genetic influences on production and reproduction traits in pigs
}

\author{
H. A. M. van der Steen (Animal Breeding Department, Agricultural University, \\ Marijkeweg 40, 6709 PG Wageningen, Netherlands)
}

Accepted: 1 August 1983

\begin{abstract}
The effect of post-natal litter size on growth and energy intake of piglets was studied by standardizing litters at 6 or 12 piglets within 24 hours after birth. Effect of standardization level on further development and first litter size of gilts and implication for genetic improvement of litter size were investigated.

Key-words: maternal effects, reproduction, litter size, selection, gilt, pig.
\end{abstract}

Introduction. An increase of litter size would improve reproductive performance in pigs. Mean litter size has been rather constant in most countries over the last decades. (Skjervold, 1979; Johansson, 1981). This means that there has been no response to selection or no selection pressure on litter size. It could also imply a deterioration in the environment or negative effects of selection for production characteristics. Heritability $\left(h^{2}\right)$ of litter size seems to be a limiting factor for genetic improvement of litter size. A negative correlation between direct genetic and maternal effect might reduce the effective heritability or response to selection (Skjervold, 1979; Rutledge, 1980; Robison, 1981). Maternal influences are partly due to the size of the litter in which a gilt is raised. Gilts raised in small litters might produce larger litters than gilts raised in large litters. The present study focussed on the effect of the post-natal maternal conditions on the fertility of the daughter.

Material and methods. Three generations of Dutch Landrace gilts were reared. The first generation (192 gilts) was purchased and the litters produced were standardized at 8 piglets within 24 hours of birth. Litters produced by the gilts of generation two were standardized at 6 (low level) or 12 piglets (high level). Thus the effect of the standardization level on production and reproduction traits was measured in gilts of generation three. Gilts were inseminated at a fixed age of approximately 255 days.

Results. Growth of litters from birth to weaning at five weeks of age, expressed per piglet, at the high standardization level was $24 \%$ lower than those at the low level. From weaning to 56 days of age the difference was $8 \%$. This resulted in a weight at 56 days of 15.8 and $18.7 \mathrm{~kg}$ for gilts raised at the high and low levels respectively. Milk energy intake was ca. $26 \%$ lower for piglets raised in large compared with small litters. The intake of milk and creep feed (ME) from 21 days to weaning was reduced by ca. $19 \%$.

The estimate of standardization level effect on litter size obtained from halo- 
thane negative gilts, after correction for oestrus number at insemination, was -0.48 piglets (high-low). The realized difference in standardization level was 5.4 piglets which resulted in an estimate of the post-natal component of the ' $m$ value', defined by Falconer $(1965)$ of $-0.09(-0.48 / 5.4)$. The coefficient $m$ is the partial regression coefficient of daughters' phenotypic value on mothers' phenotypic value for litter size in the absence of genetic variation among the mothers. This $m$ value can be split into a pre- and post-natal component $m_{1}$ and $m_{2}$.

Implication for genetic improvement of litter size. Maternal effects influence the daughter-dam regression coefficient $\left(b_{\mathrm{PP}^{\prime}}\right)$ and the regression coefficient of additive genetic value on phenotypic value $\left(b_{\mathrm{AP}}\right)$.

$$
b_{\mathrm{PP}^{\prime}}=h^{2}\left(\frac{1}{2-m}\right)+m ; b_{\mathrm{AP}}=h^{2}\left(1+\frac{m}{2-m}\right)
$$

Maternal influences affect the response to selection in three ways. Firstly $b_{\mathrm{AP}}$ and thus the response to selection, will be changed. A value of -0.1 or -0.2 for $m$ reduced this regression coefficient by 5 and $9 \%$ respectively. Secondly, maternal effects result in an important permanent negative effect on litter size as, in a selection programme for litter size, the next generation of gilts will be born and raised in large litters. Thirdly, the selection response (larger litters) will result in a larger permanent negative effect. So the genetic implications of maternal effects on litter size are limited. Selection will result in an additive genetic response. The permanent negative environmental effect on litter size, if replacement gilts are born and raised in large litters, does reduce the phenotypic value. To a large extent, standardization of litters will remove this, from an economic point of view, unfavourable effect.

\section{References}

Falconer, D. S., 1965. Maternal effects and selection response. Genetics Today. Proceedings 11 th International Congress of Genetics (The Hague): 763-774.

Johansson, K., 1981. Some notes concerning the genetic possibilities of improving sow fertility. Livestock Production Science 8: 431-447.

Robison, O. W., 1981. The influence of maternal effects on the efficiency of selection: a review. Livestock Production Science 8: 121-137.

Rutledge, J. J., 1980. Fraternity size and swine reproduction. 1. Effect on fecundity of gilts. 2. Genetical consequences. Journal of Animal Science 51: 868-874.

Skjervold, H., 1979. What about the genetic improvement of litter size? Acta Agriculturae Scandinavica, Supplement, 21: 176-184.

This synopsis is based on a doctoral thesis, Agricultural University, Wageningen, 1983. 113 pp., 29 figs., 49 tables, 70 refs. English, Dutch summary.

Available as paper copy (order R001P, $f 30$ including postage) or microfiches (order R001M, f 17.50 including postage) at: NARD, clo Pudoc; P.O. Box 4, 6700 AA Wageningen, Netherlands (telex 45015 blhwg $\mathrm{nl}$ ). 